\title{
Blood and platelet transfusion from a donor with presymptomatic Covid-19
}

\author{
Konstantinos Liapis ${ }^{1} \cdot$ Menelaos Papoutselis ${ }^{1} \cdot$ Georgios Vrachiolias ${ }^{1}$ (i) $\cdot$ Christina Misidou $^{1}$. \\ Emmanouil Spanoudakis ${ }^{1} \cdot$ Zoe Bezirgiannidou $^{1,2} \cdot$ Aikaterini Pentidou $^{1} \cdot$ Theocharis Konstantinidis $^{2,3}$. \\ loannis Kotsianidis ${ }^{1}$
}

Received: 26 October 2020 / Accepted: 2 November 2020 / Published online: 13 November 2020

(C) Springer-Verlag GmbH Germany, part of Springer Nature 2020

\section{Dear Editor,}

The Covid-19 pandemic has major implications for blood transfusion. Because SARS-CoV-2 is a new virus, its potential for transfusion transmission, including by an asymptomatic or presymptomatic donor, is uncertain [1]. The risk for transmitting other coronaviruses including SARS-CoV by transfusion is currently considered low $[1,2]$. SARS-CoV-2 RNA has been detected in the bloodstream of infected individuals [3, 4], but it is unknown whether this may translate to transmissibility. Data relating to the number of blood donors with presymptomatic infection when donating are limited [5], and therefore, an effort to collect data is important to determine whether transfusions carry a risk of transmission. We report the transfusion of blood and platelets from a presymptomatic donor.

The donor was a 48-year-old man who donated blood on August 12, 2020, at the Hippokration Blood Institute in Thessaloniki. At the time of donation, he had no symptoms of an infectious illness. According to the current blooddonation practice, he underwent screening for symptoms and elevated temperature before entering facilities and donation site. Donor blood was separated into red cells, platelets, and

This manuscript contains original material that has not been reported or published elsewhere or submitted previously to another journal.

Georgios Vrachiolias

george_vrachiolias@yahoo.com

1 Department of Hematology, University Hospital of Alexandroupolis, Democritus University of Thrace Medical School, Dragana Area, 68100 Alexandroupolis, Greece

2 Blood Transfusion Institute, University Hospital of Alexandroupolis, Alexandroupolis, Greece

3 Laboratory of Molecular Hematology, Department of Medicine, Democritus University of Thrace Medical School,

Alexandroupolis, Greece plasma. The red-blood-cell unit was transfused in Thessaloniki on August 14 and the platelet unit was transfused in Alexandroupolis on August 17, with no adverse reactions.

Patient 1, who received the red-cell transfusion, was an 86year-old woman admitted to the hospital because of anemia. Patient 2, who received the platelet unit, was a 61-year-old man who had been diagnosed with myelodysplastic syndrome in February 2017. He achieved complete remission with azacitidine but disease relapsed and underwent unrelateddonor hematopoietic-cell transplantation in October 2018. He again relapsed in July 2019, and at the time of transfusion, he was treated with azacitidine and glasdegib.

On August 20, the Hippokration Blood Institute was notified about a positive nasopharyngeal SARS-CoV-2 test in the donor. The donor was evaluated on August 20. During this evaluation, he reported that he had become ill with fever and headache on August 14. No family members or close contacts had been ill. Nasopharyngeal swab testing in both patients was negative on August 21. According to the Hellenic National Public Health Organization, each patient was followed-up for 4 weeks, during which they did not develop signs or symptoms of Covid-19. A second nasopharyngeal test in patient 27 days later was also negative. Testing for anti-SARS-CoV-2 antibody at week 4 was negative. The donor recovered at home, with supportive care and isolation.

SARS-CoV-2 RNAemia has been detected in $15 \%$ of hospitalized patients with Covid-19 [6]. According to WHO interim guidance [7], hemovigilance systems should be established to monitor any potential cases of SARS-CoV-2 transfusion transmission. Donor screening is crucial for reducing the risk of virus transmission during the pandemic [5]. The European Center for Disease Prevention and Control suggests a 21-day precautionary deferral from blood donation after any possible exposure to SARS-CoV-2 [2]. Moreover, collection of post-donation information is of critical importance in determining whether blood and platelet transfusions from 
presymptomatic donors carry a risk of transmission. We suggest that specific post-donation information protocols should be established to monitor SARS-CoV-2 in donors. Donors should be encouraged to promptly report any illness in the days after donation and asked to report any contact with a confirmed case prior to donation. This concern, also important for safety of staff and other donors, has been highlighted in the present report.

As Covid-19 continues to explode, sharing experience and information is necessary to address emerging problems in the transfusion chain, from donor to recipient. Our findings and previous reports $[8,9]$ support the conclusion that transfusion from presymptomatic donors did not result in transmission, even in severely immunocompromised patients.

Author contribution All authors have contributed to the writing of the manuscript. All authors agree to the submission of this manuscript to Annals of Hematology.

\section{Compliance with ethical standards}

Conflict of interest The authors declare that they have no conflicts of interest.

Ethical approval This article does not contain any studies with human participants or animals performed by any of the authors.

Informed consent Informed consent was obtained from the donor and the patients.

\section{References}

1. Chang L, Yan Y, Wang L (2020) Coronavirus disease 2019: coronaviruses and blood safety. Transfus Med Rev 34:75-80. https://doi.org/10.1016/j.tmrv.2020.02.003
2. European Centre for Disease Prevention and Control. Coronavirus disease 2019 (COVID-19) and supply of substances of human origin in the EU/EEA-first update (2020). https://www.ecdc.europa.eu/ sites/default/files/documents/COVID\%2019-supply-substanceshuman-origin-first-update.pdf. Accessed 1 Sept 2020

3. Kwon SY, Kim EJ, Jung YS, Jang JS, Cho NS (2020) Post-donation COVID-19 identification in blood donors. Vox Sang. https://doi.org/ 10.1111/vox.12925

4. Chang L, Zhao L, Gong H, Wang L, Wang L (2020) Severe acute respiratory syndrome coronavirus 2 RNA detected in blood donations. Emerg Infect Dis 26:1631-1633. https://doi.org/10.3201/ eid2607.200839

5. Stanworth SJ, New HV, Apelseth TO, Brunskill S, Cardigan R, Doree C, Germain M, Goldman M, Massey E, Prati D, Shehata N, So-Osman C, Thachil J (2020) Effects of the COVID-19 pandemic on supply and use of blood for transfusion. Lancet Haematol 7:e756e764. https://doi.org/10.1016/S2352-3026(20)30186-1

6. Huang C, Wang Y, Li X, Ren L, Zhao J, Hu Y, Zhang L, Fan G, Xu J, Gu X, Cheng Z, Yu T, Xia J, Wei Y, Wu W, Xie X, Yin W, Li H, Liu M, Xiao Y, Gao H, Guo L, Xie J, Wang G, Jiang R, Gao Z, Jin Q, Wang J, Cao B (2020) Clinical features of patients infected with 2019 novel coronavirus in Wuhan, China. Lancet 395:497-506. https://doi.org/10.1016/S0140-6736(20)30183-5

7. WHO. Maintaining a safe and adequate blood supply during the pandemic outbreak of coronavirus disease (COVID-19): interim guidance (2020). https://apps.who.int/iris/handle/10665/331523. Accessed 10 Sept 2020

8. Cho HJ, Koo JW, Roh SK, Kim YK, Suh JS, Moon JH, Sohn SK, Baek DW (2020) COVID-19 transmission and blood transfusion: a case report. J Infect Public Health 13:1678-1679. https://doi.org/10. 1016/j.jiph.2020.05.001

9. Essa MF, Elbashir E, Batarfi K, Alharbi M (2020) Lack of transmission of SARS-CoV-2 by platelet transfusion from a COVID-19positive donor in a hematopoietic stem cell transplantation patient. Pediatr Blood Cancer 19:e28658. https://doi.org/10.1002/pbc.28658

Publisher's note Springer Nature remains neutral with regard to jurisdictional claims in published maps and institutional affiliations. 